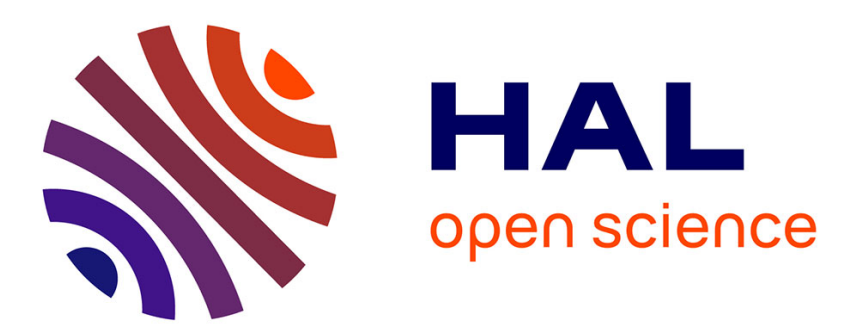

\title{
New spacer designs for the performance improvement of the zigzag spacer configuration in spiral-wound membrane modules
}

Mounir Amokrane, Djamel Sadaoui, Michel Dudeck, Chrysafenia P. Koutsou

\section{- To cite this version:}

Mounir Amokrane, Djamel Sadaoui, Michel Dudeck, Chrysafenia P. Koutsou. New spacer designs for the performance improvement of the zigzag spacer configuration in spiral-wound membrane modules. Desalination and Water Treatment, 2015, 57 (12), pp.5266-5274. 10.1080/19443994.2015.1022003 . hal-01291685

\section{HAL Id: hal-01291685 \\ https://hal.sorbonne-universite.fr/hal-01291685}

Submitted on 21 Mar 2016

HAL is a multi-disciplinary open access archive for the deposit and dissemination of scientific research documents, whether they are published or not. The documents may come from teaching and research institutions in France or abroad, or from public or private research centers.
L'archive ouverte pluridisciplinaire HAL, est destinée au dépôt et à la diffusion de documents scientifiques de niveau recherche, publiés ou non, émanant des établissements d'enseignement et de recherche français ou étrangers, des laboratoires publics ou privés. 


\title{
New spacer designs for the performance improvement of the zig-zag spacer configuration in spiral-wound membrane modules
}

\author{
Mounir Amokrane ${ }^{1}$, Djamel SAdAoui ${ }^{1}$, Michel DudeCK ${ }^{2}$, Chrysafenia P. KOUTSOU $^{3}$ \\ ${ }^{1}$ Laboratoire de Mécanique, Matériaux et Energétique (L2ME), Faculté de Technologie, \\ Université de Bejaia, 06000 Bejaia, Algérie \\ ${ }^{2}$ Institut d'Alembert, CNRS et Université Pierre et Marie Curie, 4 place Jussieu, 75252 Paris, \\ France \\ ${ }^{3}$ Chemical Process Engineering Research Institute - CERTH, P.O. Box 60361, GR 570 01, \\ Thermi-Thessaloniki, Greece \\ ${ }^{1} \mathrm{Tel}:+213$ 664222008, Email : mounir139@live.fr \\ ${ }^{1}$ Tel : +213 794697459, Email : sadaouidjamel@yahoo.fr \\ ${ }^{2} \mathrm{Tel}:+33$ 144278716, Email : dudeck@dalembert.upmc.fr \\ ${ }^{3} \mathrm{Tel}$ : +30 2310 498181, Email : ckoutsou@cperi.certh.gr
}

\begin{abstract}
The zig-zag configuration of spacers appears to have more advantages compared to the socalled "submerged" configuration for improving the performance of the reverse osmosis (RO) process; however, spacers attached to membrane walls may promote fouling. A twodimensional numerical model coupling fluid dynamics and mass transfer was developed to study the impact of new design spacers, such as ellipse and oval shapes to control concentration polarization and reduce pressure drop. To improve spacer performance spacers considered here are "tilted" and their performance is compared with the reference spacers (circular). It is shown that elliptical and oval spacers lead to significant reduction of the pressure drop when compared to circular spacers. Based on numerical prediction, mass transfer is enhanced, pressure drop minimized and the probability of fouling is decreased if oval spacers are tilted at $20^{\circ}$ compared to the widely used conventional spacers.
\end{abstract}

Keywords: Concentration polarization; CFD; New spacer designs; Water treatment; Tilted spacers.

\section{Introduction}

Desalination of seawater by reverse osmosis (RO) consists on applying a gradient of pressure higher than osmotic pressure across a selective membrane. Currently, spiral-wound membrane (SWM) modules are the most prevalent in the industry and the use of CFD to predict flow field was extensively discussed in the literature [1,2]. Unlike the existence of various models that can predict the concentration polarization along membranes surfaces in empty channels [3, 12], they does not reflect industrial configurations. However more realistic 
models may be found in two-dimensional [13-21] or in three-dimensional [22-24]. The use of spacers in membranes channels is essential to improve the mass transfer, however it generates a higher pressure drop than an empty channel which requires more energy consumption. Besides, the high salt accumulation near spacers attached to the membrane surfaces (i.e. zigzag configuration) could accelerates the fouling and decreases the performances of the process. In the literature, we can distinguish the important contribution made by Shwinge et al [13-16] that have optimized the geometrical parameters such as the diameter and the distance between obstacles for different configurations for a wide range of feed Reynolds number. Furthermore, Cao et al [17] have tested several configurations of spacers and studied the shear stress created by the location of obstacles for a turbulent flow. Later Koutsou et al [18] introduced a regular array of submerged cylinders to better understand the flow behavior and the study of statistical parameters. Concentration polarization along membranes walls was considered by Subramani et al [19] that developed a lab-scale finite element model and simulated different spacer configurations with the presence of only one membrane. Soon thereafter, Wardeh and Morvan [20, 21] used channels having two membranes walls and studied the effect of the curvature.

Square obstacle shapes were used by $\mathrm{Ma}$ et al $[25,26]$ to study the concentration polarization and the permeation flux for a single spacer and for various configurations with variation in mesh length. Further Geraldes et al [27-29] had opted for a slit filled with ladder type spacers to investigate the flow structure and the solute concentration distribution.

A literature survey related to this topic revealed that some studies have aimed to design a new form of spacers to optimize the process [30-35]. In this regard, Dendukuri et al [30] have used different concave shapes with a variable geometrical ratio. One of their interesting findings was that new forms can reduce the pressure drop compared to the conventional form. In addition, Ahmad et al [31,32] focused in their paper on the impact of different spacers (circular, square and triangular) on hydrodynamics and concentration polarization. The results indicated that for operational velocities cylindrical spacer can generate lower concentration factor compared to rectangular spacer. It is also found that for turbulent flow triangular filaments causes the highest degree of concentration minimization ability and pressure drop followed by square and circular filaments. However, Guillen and Hoek [34] developed a multi-scale model linking the microscopic and macroscopic transport phenomena to study the impact of new spacer designs (square, ellipse and wing) on the mass transfer, pressure drop, water quality of the product, and energy consumption. It is concluded that for low salinity waters, some of these unconventional shapes can reduce energy consumption, and there is no significant effect for high salinity waters.

As can be seen in literature, some works introduced new designs of spacers to reduce concentration polarization along membranes walls, while others tried to generate lower pressure drop, but the challenge is to control the concentration polarization as well as the minimization of the pressure drop. Unlike the case for submerged configuration [34], current numerical study introduces new spacers design such as the ellipse and the oval attached to membranes surfaces in zigzag configuration to evaluate their ability to enhance mass transfer coefficient, minimize the hydraulic loss and control the concentration polarization along membranes walls. Results will be compared with the circular form widely used in spiralwound membrane modules. Special attention will be paid to the effect of tilting of new spacers on flow patterns and mass transfer in order to optimize the process. The results 
obtained with tilted spacers are compared with those of the conventional spacers, with the visualization of streamlines and contours of mass fraction in vicinity of spacers.

\section{Modeling}

The physical domain of interest is a cross section of a spiral-wound membrane modules representing a zigzag configuration of seven spacers of different shapes (circle, ellipse and oval) spaced by 1 . These spacers with the same cross sections (height) are mounted between two horizontal and parallel plates of length $\mathrm{L}=85 \mathrm{~mm}$ separated by $\mathrm{H}=2 \mathrm{~mm}$. For convenience, these parameters are defined in terms of geometrical ratios such as: $d / H=0.5$ and $1 / \mathrm{H}=4,[13]$. The aspect ratio of the ellipse is $\mathrm{a} / \mathrm{b}=1 / 2$ while the oval spacers are obtained by pairing a half circle with a half ellipse, see Fig.1. Further, long entrance and exit lengths are applied to reach a fully developed flow before the first spacer and to avoid interference between the recirculation and the last spacer, [20].

(a)

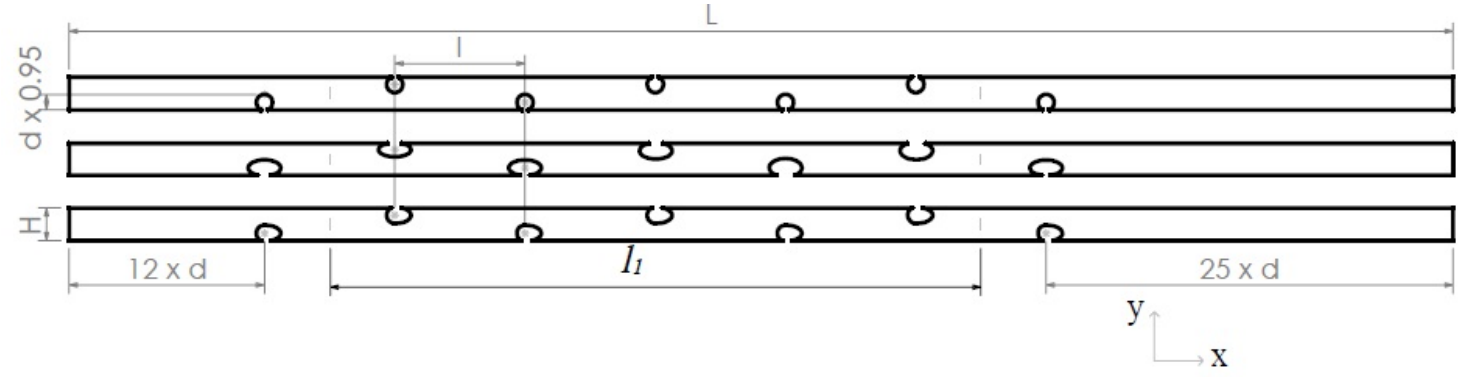

(b)

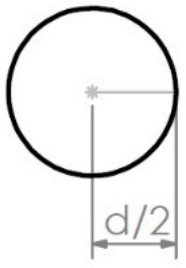

Circle

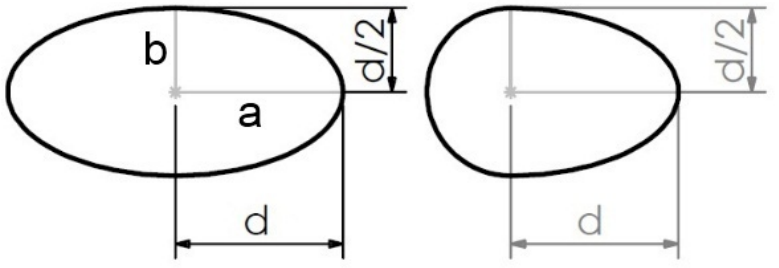

Oval

Fig.1 Dimensions of (a) the physical domain and (b) the spacer filament

The numerical model for fluid flow and mass transfer within spiral-wound membrane modules was developed under some assumptions as 2D time dependent, isothermal, laminar and incompressible. Gravity, viscous dissipation and compressibility effects are also neglected. Under these assumptions, the equations of continuity, momentum and mass transfer are cast in their dimensional form as follow: 


$$
\begin{aligned}
& \frac{\partial \rho}{\partial \mathrm{t}}+\nabla \cdot(\rho \mathbf{V})=0 \\
& \frac{\partial \rho \mathbf{V}}{\partial \mathrm{t}}+\nabla \cdot(\rho \mathbf{V} \mathbf{V})=-\nabla \cdot\left[\mu\left(\nabla \mathbf{V}+\nabla \mathbf{V}^{\mathrm{T}}\right)\right]-\nabla \mathrm{p} \\
& \frac{\partial \rho \mathrm{m}_{\mathrm{A}}}{\partial \mathrm{t}}+\nabla \cdot\left(\rho \mathbf{V} \mathrm{m}_{\mathrm{A}}\right)=\nabla \cdot\left(\rho \mathrm{D}_{\mathrm{AB}} \nabla \mathrm{m}_{\mathrm{A}}\right)
\end{aligned}
$$

In above equations $\rho, \mu, \mathbf{V}$ and $\mathrm{p}$ are the density, dynamic viscosity, velocity field and pressure while $\mathrm{m}_{\mathrm{A}}$ and $\mathrm{D}_{\mathrm{AB}}$ are the salt mass fraction and the binary diffusion coefficient of the solute $\mathrm{A}$ in the solvent $\mathrm{B}$, respectively.

A mixture of pure water and sodium chloride flows into the feed channel. The physical properties of the aqueous solution vary according to Eqs. 2-5 as described by Geraldes et al [4] and valid for a mass fraction not exceeding $0.09 \mathrm{~kg} / \mathrm{kg}$.

$$
\pi=805.1 \times 10^{5} \mathrm{~m}_{\mathrm{A}}
$$

$$
\begin{aligned}
& \mu=0.89 \times 10^{-3}\left(1+1.63 \mathrm{~m}_{\mathrm{A}}\right) \\
& \mathrm{D}_{\mathrm{AB}}=\max \left(1.61 \times 10^{-9}\left(1-14 \mathrm{~m}_{\mathrm{A}}\right), 1.45 \times 10^{-9}\right) \\
& \rho=997.1 \times\left(1.0+0.696 \mathrm{~m}_{\mathrm{A}}\right)
\end{aligned}
$$

In this work, the following boundary conditions are applied at initial time $(\mathrm{t}=0)$.

At the inlet $(\mathrm{x}=0 ; 0 \leq \mathrm{y} \leq \mathrm{H})$

$$
\mathrm{m}_{\mathrm{A} 0}=0.002 \quad \mathrm{v}=0 \quad \mathrm{u}=\mathrm{u}_{\text {。 }}
$$

At the outlet $(\mathrm{x}=\mathrm{L} ; 0 \leq \mathrm{y} \leq \mathrm{H})$ an open boundary condition is applied.

$$
\frac{\partial \mathrm{u}}{\partial \mathrm{x}}=0 \quad \frac{\partial \mathrm{v}}{\partial \mathrm{x}}=0 \quad \frac{\partial \mathrm{m}_{\mathrm{A}}}{\partial \mathrm{x}}=0
$$

On the spacers, the no slip and no solute flux are assumed

$$
\mathrm{u}=0 \quad \mathrm{v}=0 \quad \frac{\partial \mathrm{m}_{\mathrm{A}}}{\partial \mathrm{x}}=0
$$

The membrane walls $(y=0, y=H)$ are impermeable to the salt with a salt rejection $R=0.99$ and a constant membrane resistance $R_{m}=1562 \times 10^{14} \mathrm{~m}^{-1}$. These values were obtained experimentally for an aqueous solution of $\mathrm{NaCl}$ in empty membrane channel at $\Delta \mathrm{P}=8.103$ $10^{5} \mathrm{~Pa}$.

A coupled boundary condition which links concentration polarization and permeation flux is applied on membranes surfaces $(y=0 ; y=H ; 0 \leq x \leq L)$

$\mathrm{u}=0$ 
$\mathrm{v}= \pm \mathrm{J}_{\mathrm{v}}= \pm \frac{1}{\mathrm{R}_{\mathrm{m}} \mu_{\mathrm{w}}}(\Delta \mathrm{P}-\Delta \pi)$

$\mathrm{J}_{\mathrm{v}} \cdot \mathrm{R} \cdot \mathrm{m}_{\mathrm{A}}=-\mathrm{D}_{\mathrm{AB}} \frac{\partial \mathrm{m}_{\mathrm{A}}}{\partial \mathrm{y}}$

The positive sign $(+)$ indicates the upper membrane surface, while the negative $(-)$ represent the lower membrane surface. In previous equation, $\mu_{\mathrm{w}}$ is the dynamic viscosity of the pure water and $\mathrm{J}_{\mathrm{v}}$ the permeate flux; which vary along membranes walls according to the transmembrane pressure $\Delta \mathrm{P}$ and osmotic pressure $\Delta \pi$.

Concentration polarization due to the accumulation of the rejected solutes on the membrane walls promotes the formation of a polarized layer thickness along membranes surfaces. From film theory this layer thickness is calculated using Eq. 12, [6].

$\delta=\ln \left(\frac{\mathrm{m}_{\mathrm{Am}} \mathrm{R}}{\mathrm{m}_{\mathrm{A} 0}-(1-\mathrm{R}) \mathrm{m}_{\mathrm{Am}}}\right) \times \frac{\mathrm{D}_{\mathrm{AB}}}{\mathrm{J}_{\mathrm{v}}}$

Therefore, the mass transfer coefficient for un-fouled membrane is linearly related to concentration layer thickness by Eq. 11, [6]:

$\mathrm{k}=\frac{\mathrm{D}_{\mathrm{AB}}}{\delta}$

\section{Numerical procedure}

Governing equations of the continuity, momentum and mass transfer (Eq. 1) with the prescribed boundary conditions are solved numerically by the finite volume method under non-uniform grid system in $\mathrm{x}$ and $\mathrm{y}$ directions. The solver specified uses a pressure correction based on iterative SIMPLE algorithm. The convective terms are discretized using the second order upwind scheme whereas a second order Adams-Moulton scheme is applied for the time discretization. The time step $(\Delta \mathrm{t})$ used for all simulations is $1.10^{-4} \mathrm{~s}$ by adopting the courant number formulation which gives $(\Delta t)$ as a function of the mesh and the flow velocity [18]. To check the convergence of the sequential iterative solution, the normalized residual is calculated for the mass, momentum and mass transfer equations. Thus the convergence is obtained when the residual factor becomes smaller than $10^{-8}$. The computational grid size contains 44536 nodes for channels having circular or elliptical spacers and 45446 nodes for channel with oval spacers sufficient to achieve a solution independent of the mesh. Moreover, the mesh is refined and focused near the membranes and spacers where the largest gradients of velocity and mass fraction are located. 


\subsection{Validation}

Developed numerical model has been validated against the results reported by Pinho et al [5] and Ahmed et al [6] for an empty channel (without spacer) of length $\mathrm{L}=200 \mathrm{~mm}$ and height $\mathrm{H}=0.7 \mathrm{~mm}$ with the same assumptions and boundary conditions. Fig. 2 shows the profiles of the concentration polarization factor $\Gamma=\left(\mathrm{m}_{\mathrm{A}}-\mathrm{m}_{\mathrm{A} 0}\right) / \mathrm{m}_{\mathrm{A} 0}$ for different trans-membrane pressures along the membrane wall. The comparisons are in excellent agreements, providing sufficient confidence in present computations.

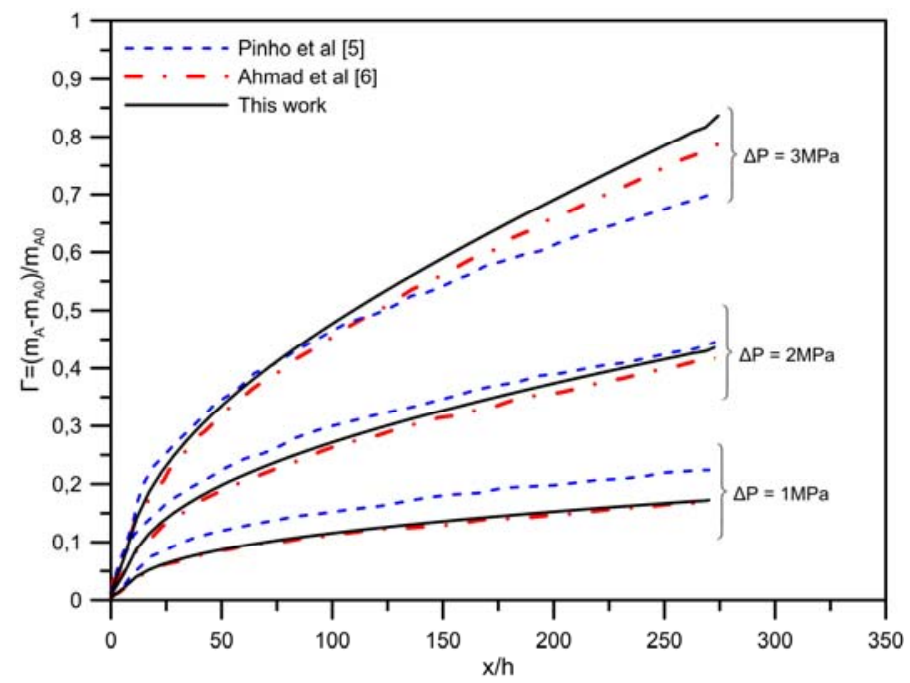

Fig.2 Comparison of concentration polarization factor between current work and references [5] and [6] for $\mathrm{Re}_{\mathrm{ch}}$ $=1300$

\section{Results and discussion}

Present simulations were done with feed Reynolds number based on channel height $\left(\operatorname{Re}_{c h}=\rho u_{0} H / \mu\right)$ not exceeding 380 which is sufficient to represent the flow velocities in spiral-wound membrane modules [18]. The lower membrane is chosen to analyze the evolutions along the length noted $\left(l_{1}\right)$, see Fig.1; it does not include the first and the last spacers that have different hydrodynamic field compared to the interior spacers.

For a Reynolds number up to 380 , the flow remains steady with no temporal variation in velocity or pressure at any point inside studied channels as time progresses (from $t=2 s$ ) as expected in reference [36] for $\mathrm{Re}_{\mathrm{ch}} \leq 340$ for the circular spacers . The examination of flow pattern exhibits the same structure as described in references [16], [36] and [37] regardless the chosen spacer. As noted in Fig. 3 circular spacer produces higher velocity magnitude followed by oval and ellipse spacers, it is also shown that the main recirculation regions formed behind the spacers are larger in the case of circular shape. 


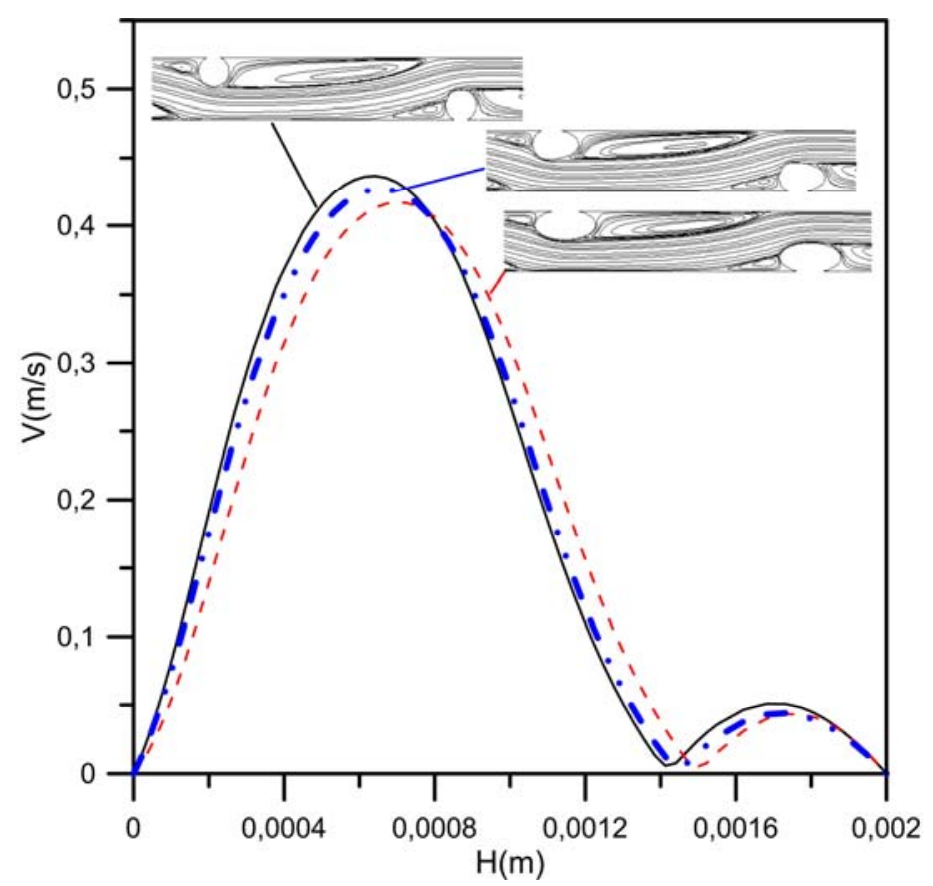

Fig.3 Velocity magnitude along the channel height at $\mathrm{x}=44 \mathrm{~mm}$ from the inlet for $\mathrm{Re}_{\mathrm{ch}}=380$

Concentration polarization along the lower membrane surface $\left(l_{1}\right)$ is plotted in Fig. 4a. The stagnation of flow near spacers attachment (low shear stress) promotes high concentration (see Fig. 5). Upstream, the highest values are obtained with elliptical spacers; while downstream, both ellipse and oval spacers admit maximum values. At the separation zone, the concentration is slightly higher with elliptical spacers than with other spacer shapes. Mass transfer coefficient $k$ predicted numerically shows that maximum values (peaks) generated by circular spacer are higher than those obtained with oval and ellipse spacers, Fig. 4b.
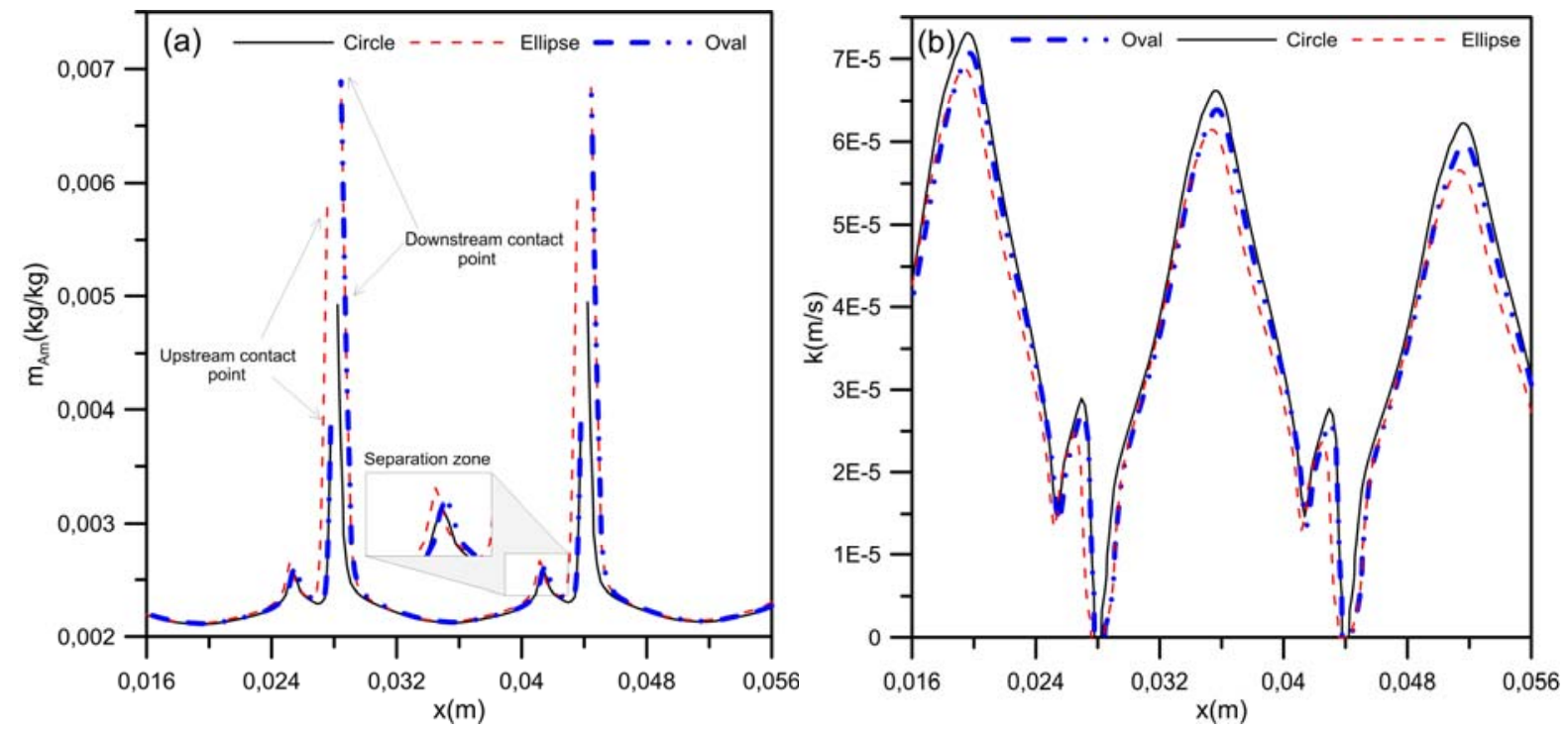

Fig.4 Salt mass fraction (a) and mass transfer coefficient (b) along the lower membrane surface $\left(l_{1}\right)$ for $\operatorname{Re}_{\mathrm{ch}}=240$ 


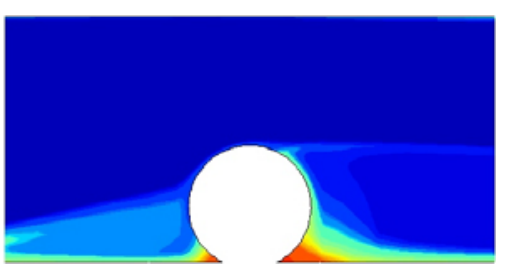

Circle

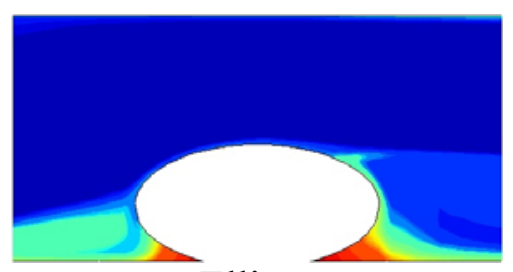

Ellipse

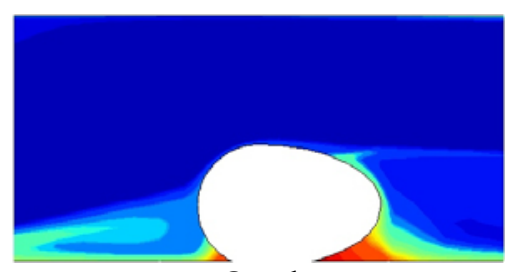

Oval

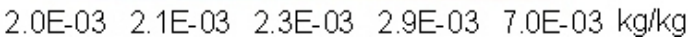

Fig. 5 Contours of salt mass fraction in the vicinity of the fifth spacer for $\operatorname{Re}_{\mathrm{ch}}=240$

Indeed, Averaged concentration polarization layer thickness $(\bar{\delta})$ and mass transfer coefficient $(\bar{k})$ along the lower membrane surface $\left(l_{1}\right)$ for different spacer shapes are investigated for different Reynolds number as illustrated in Figs. 6a and 6b. As can be seen the concentration polarization layer thickness generated by elliptical spacers remains higher than other shapes (Fig.6a) which is due essentially to the high accumulation of salt in recirculation formed between spacers and membranes surface (cf. Fig.5). Whereas, the lowest values of $(\bar{\delta})$ are generated by circular spacers. The mass transfer coefficient related mainly to the concentration polarization layer thickness corresponding to circular spacers is greater compared to other shapes. Moreover, it is observed that the difference (deviation) increases with the increasing of Reynolds.

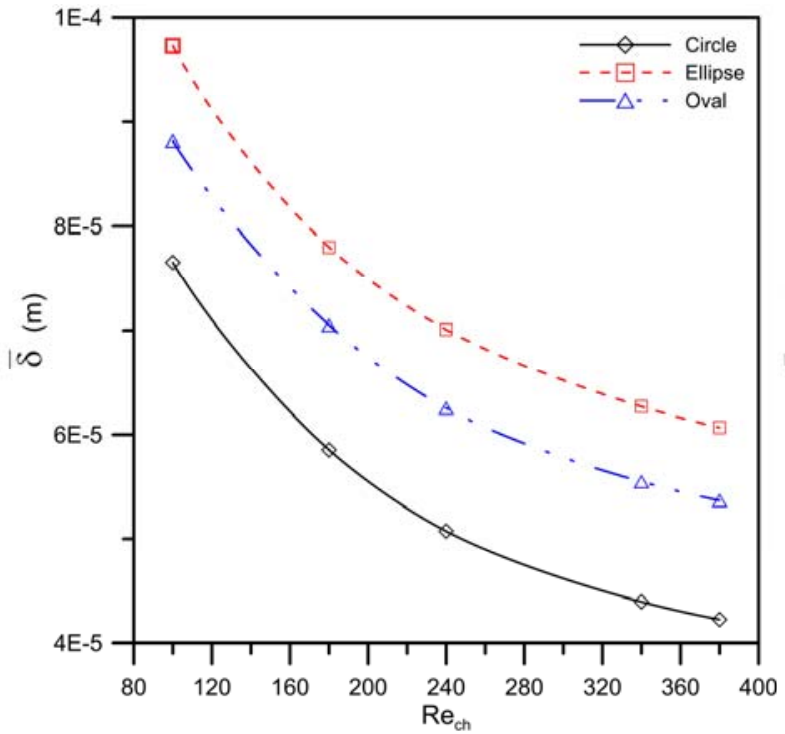

(a)

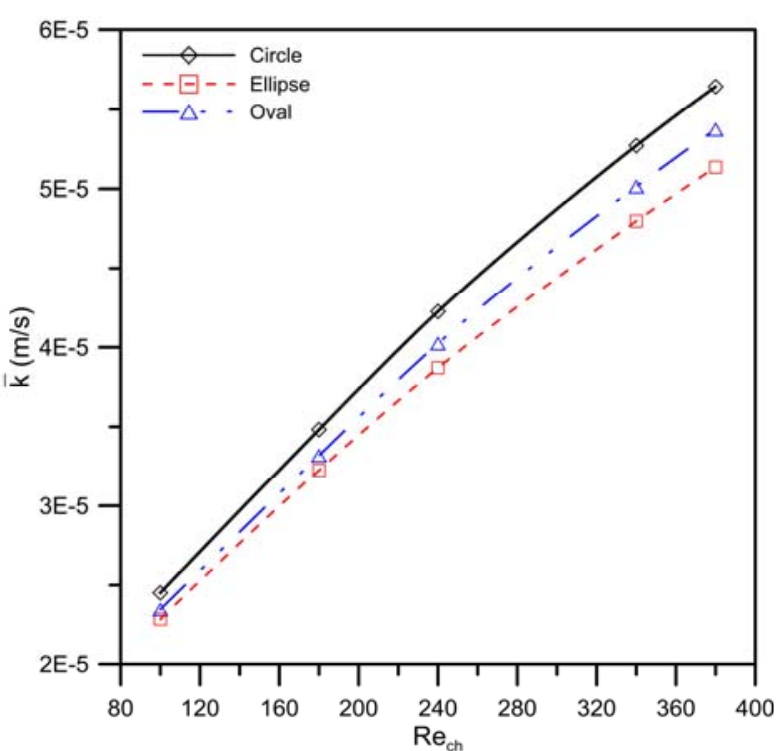

(b)

Fig.6 Average concentration polarization layer thickness (a) and mass transfer coefficient (b) along the lower membrane surface $\left(l_{1}\right)$ for various spacer geometries 


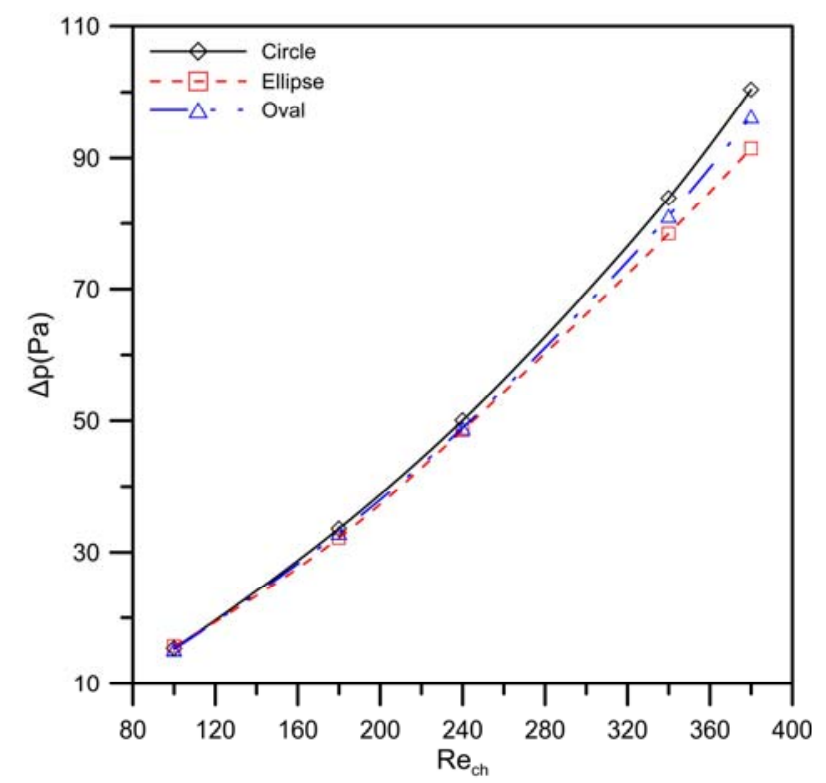

Fig.7 Axial pressure drop along $\left(l_{1}\right)$ generated with different spacer shapes.

It is noteworthy that axial pressure drop is strongly affected by the changes in flow direction, the viscous and form drag [30]. Thus, Fig. 7 exhibits the pressure drop along a straight line $\left(1_{1}\right)$ located at $(y=H / 2)$ for different spacers geometries. These results highlighted that low Reynolds values $\left(\mathrm{Re}_{\mathrm{ch}} \leq 100\right)$ does not entail any significant deviation in pressure drop for all spacer geometries. However the deviation grows with the increase of feed Reynolds number. It's also, noted that circular spacer produces largest pressure drop due to the accelerated flow generated with this geometry followed by oval and elliptic spacers (see, Fig. 3).

\subsection{Effect of inclination}

Although, tilting non-conventional spacers is not realistic however, it can be theoretically a way to optimize the process and control the concentration polarization along membranes walls. In this regard, several tests were performed with tilted spacers (ellipse and oval). As the inclination of ellipse produces a larger pressure drop [34], we only consider the effect of tilting oval spacers $\left(0 \leq \varphi \leq 20^{\circ}\right)$ as shown in Fig. 8 and results will be compared with those obtained with circular shape.

(a)

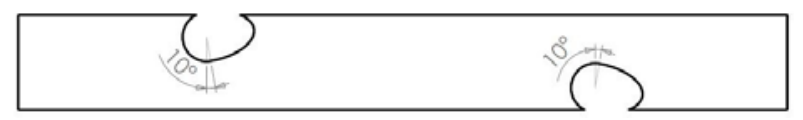

(b)

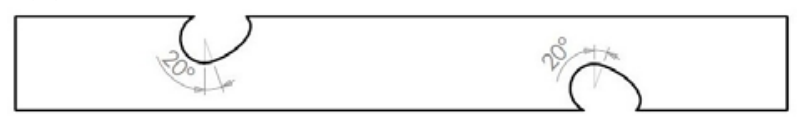

Fig.8 Physical domain (cell) with tilted oval spacer (a) $\varphi=10^{\circ}$ and (b) $\varphi=20^{\circ}$ 
Flow pattern and mass fraction contours are visualized in the vicinity of the fifth spacer as depicted in Fig. 9. In such cases, it's observed a similar flow field and salt mass fraction upstream the spacers. Downstream, the stagnant zone decreases considerably when the oval spacer is tilted with $20^{\circ}$, consequently the accumulated solute decreases comparatively to the circular shape.

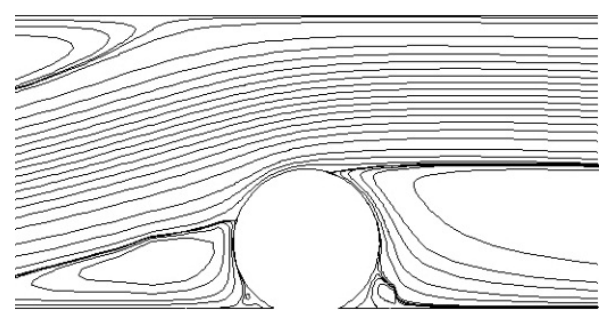

(a)

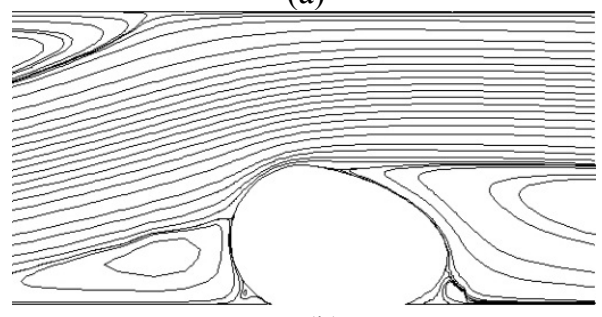

(b)

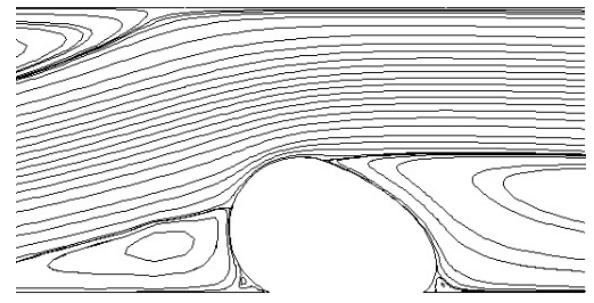

(c)

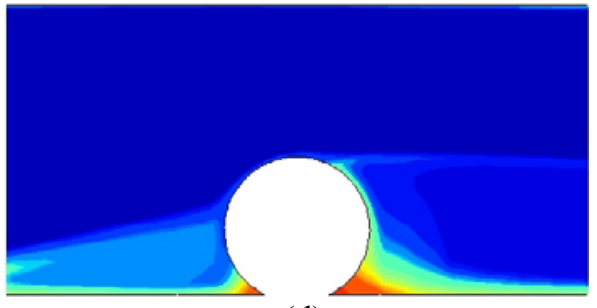

(d)

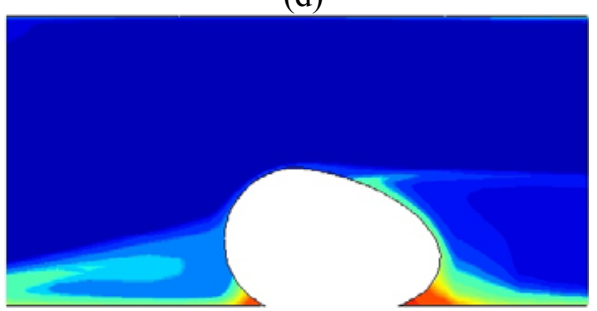

(e)

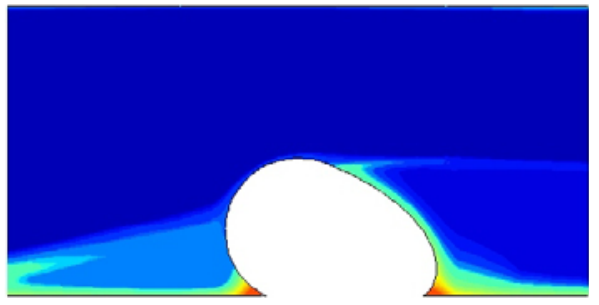

(f)

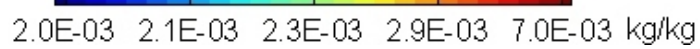

Fig.9 Streamlines (a, b, c) and mass fraction contours (d, e, f $)$ around at the fifth spacer $\left(\operatorname{Re}_{\mathrm{ch}}=380\right)$

Fig. 10 allows us to analyze concentration polarization along the lower membrane surface $\left(1_{1}\right)$ for circular and oval spacers inclined with $10^{\circ}$ and $20^{\circ}$. It's clear that the concentration near the downstream contact point is lower when the oval spacer is oriented with $20^{\circ}$ compared to other spacers, unlike upstream flow where the profiles are similar. It should be noted that oval spacer tilted with $20^{\circ}$ induced a lower concentration downstream than upstream. 


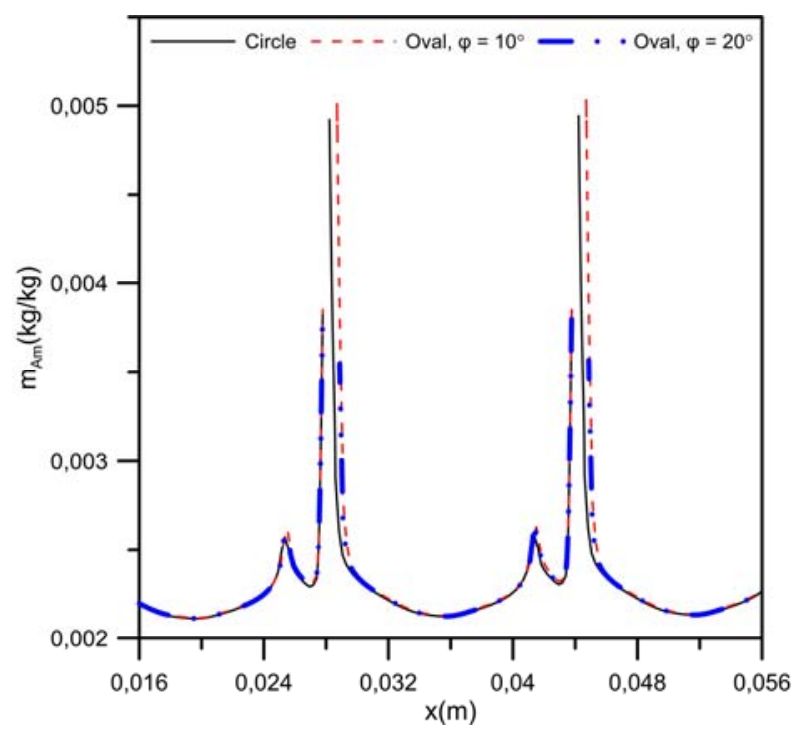

Fig.10 Salt mass fraction distribution along the lower membrane $\left(l_{1}\right)$ for circular and oval spacers $\left(\operatorname{Re}_{\mathrm{ch}}=380\right)$

Average concentration polarization layer thickness $(\bar{\delta})$ and mass transfer coefficient $(\bar{k})$ along the lower membrane surface $\left(l_{1}\right)$ for circular and oval spacers tilted with $10^{\circ}$ and $20^{\circ}$ are shown in Figs. 11a and 11b, respectively. Concentration layer thickness generated with oval spacer inclined at $20^{\circ}$ is less than that induced with circular and oval spacer tilted with $10^{\circ}$ whatever the studied Reynolds number. From $\operatorname{Re}_{\mathrm{ch}}=100$ to 340 , oval spacer tilted with $10^{\circ}$, induces largest layer thickness compared to circular shape, however beyond $\operatorname{Re}_{\mathrm{ch}}=340$, the thickness generated with circular spacer is similar to that observed with the oval shape tilted at $10^{\circ}$. Further, for low Reynolds numbers (100-180), an identical mass transfer coefficient is obtained with both oval inclined to $20^{\circ}$ and circle, beyond $\mathrm{Re}_{\mathrm{ch}}=240$, the oval spacer tilted with $20^{\circ}$ generates a higher mass transfer coefficient compared to other types of spacers.

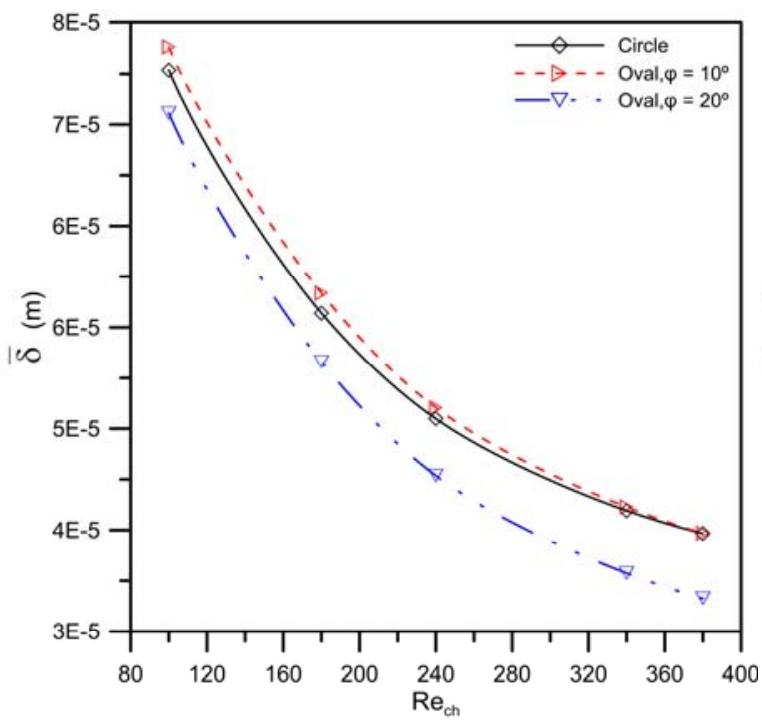

(a)

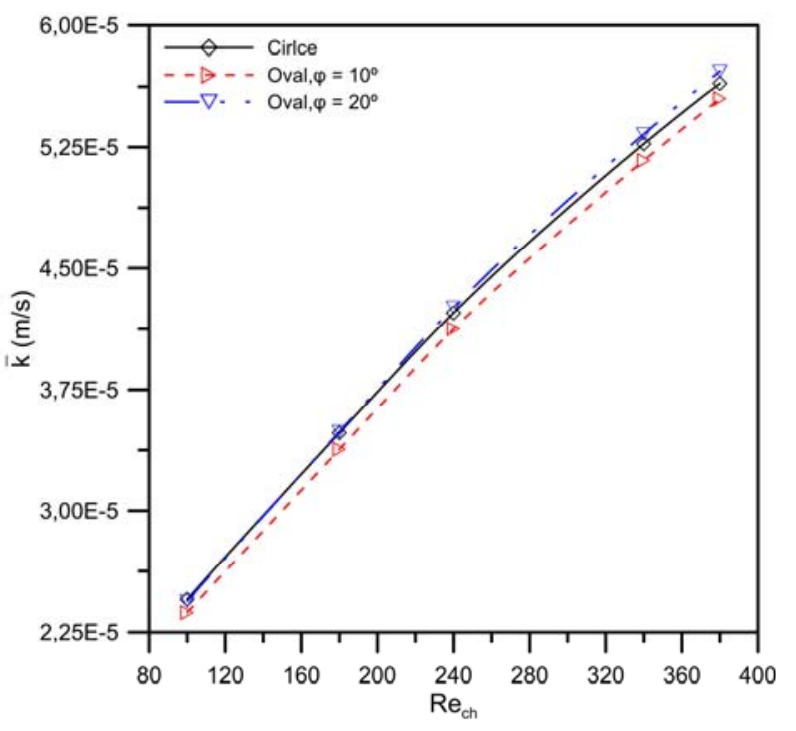

(b)

Fig.11 Average concentration polarization layer thickness (a) and mass transfer coefficient (b) along the lower membrane surface $\left(l_{1}\right)$ for circular and oval tilted spacers 
The examination of Fig.12 shows the axial pressure drop along the straight line $\left(1_{1}\right)$ located at $(\mathrm{y}=\mathrm{H} / 2)$ for different types of spacers. The result highlights no significant change in pressure drop for low feed Reynolds number. Although; beyond $\mathrm{Re}_{\mathrm{ch}}=180$, the deviation starts to grow with lowest values for oval spacers tilted respectively at $10^{\circ}$ and $20^{\circ}$. Statistically, the gain in pressure achieves $3.44 \%$ and $2.90 \%$ when oval spacer is tilted with $10^{\circ}$ and $20^{\circ}$, respectively.

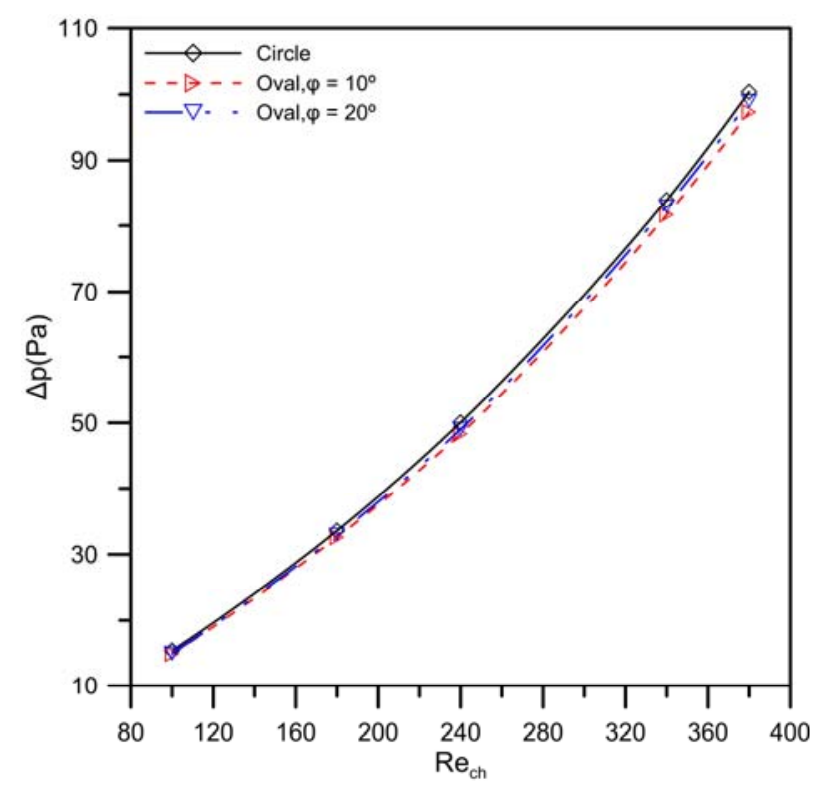

Fig.12 Axial pressure drop along $\left(l_{1}\right)$ for circle and oval tilted spacers

\section{Conclusion}

CFD model that couples fluid dynamics and mass transfer in spiral wound membrane modules for the zigzag configuration, was developed to investigate the impact of new spacer designs on concentration polarization, mass transfer coefficient and pressure drop in reverse osmosis process. The results highlight that the incorporation of new spacer designs, such as elliptic and oval shapes, generates lower pressure drop compared to conventional geometries. This is in accordance with previous work [34]. However, concentration polarization layer thickness, induced by elliptic and oval spacers, is higher compared to that of a circular spacer while the mass transfer coefficient obtained with circular spacer is higher.

Although, simulation of spiral-wound modules filled with tilted new spacer designs is a numerical challenge, this study also highlights interesting findings, namely the inclination of 
oval spacer changes the flow structure in vicinity of spacers (minimize the dead zones) which may delay the fouling and enhances the mass transfer coefficient. Furthermore, axial pressure drop induced is lower compared to the circular spacer.

The idea of tilting oval spacers provides better performance compared to the circular spacers; however, the main difficulty lies in its manufacturing and design. Therefore, further studies are needed to identify the difficulties and allow easy use in the industrial field.

\section{Nomenclature}

a,b major and minor axis of ellipse (m)

$\mathrm{d} \quad$ spacer diameter $(\mathrm{m})$

$\mathrm{D}_{\mathrm{AB}} \quad$ binary diffusion coefficient $\left(\mathrm{m}^{2} / \mathrm{s}\right)$

$\mathrm{H} \quad$ channel height (m)

$\mathrm{J}_{\mathrm{v}} \quad$ permeation flux $(\mathrm{m} / \mathrm{s})$

$\mathrm{k}$ mass transfer coefficient $(\mathrm{m} / \mathrm{s})$

$l$ distance between the center of two consecutive cylinders (m)

$\mathrm{L}$ total channel length $(\mathrm{m})$

$l_{1} \quad$ studied length (m)

$\mathrm{m}_{\mathrm{A}} \quad$ salt mass fraction ( $\mathrm{kg}$ solution/ $\mathrm{kg}$ solution)

$P \quad$ pressure $(\mathrm{Pa})$

$R \quad$ intrinsic rejection coefficient $\left(1-\left(\mathrm{m}_{\mathrm{Ap}} / \mathrm{m}_{\mathrm{Am}}\right)\right)$

$\mathrm{R}_{m} \quad$ hydraulic resistance of the membrane $\left(\mathrm{m}^{-1}\right)$

$\mathrm{Re}_{\mathrm{ch}} \quad$ feed Reynolds number based on channel height $\mathrm{H}\left(\rho \mathrm{u}_{0} \mathrm{H} / \mu\right)$

$\mathrm{t}$ time

V fluid velocity field ( $\mathrm{m} / \mathrm{s})$

$\mathrm{u}, \mathrm{v} \quad$ velocity components in Cartesian coordinates $(\mathrm{m} / \mathrm{s})$

$\mathrm{x}, \mathrm{y} \quad$ Cartesian coordinates (m)

Greek letters

$\delta \quad$ concentration polarization layer thickness (m)

$\rho \quad$ density $\left(\mathrm{kg} / \mathrm{m}^{3}\right)$

$\mu \quad$ dynamic viscosity (Pa.s)

$\Delta \mathrm{P} \quad$ trans-membranaire pressure $(\mathrm{Pa})$

$\Delta \mathrm{p} \quad$ axial pressure drop $(\mathrm{Pa})$

$\Delta \mathrm{t} \quad$ time step (s)

$\Delta \pi \quad$ osmotic pressure $(\mathrm{Pa})$

$\Gamma \quad$ concentration polarization factor $\left(\left(\mathrm{m}_{\mathrm{A}}-\mathrm{m}_{\mathrm{A} 0}\right) / \mathrm{m}_{\mathrm{A} 0}\right)$

$\varphi \quad$ inclination $\left({ }^{\circ}\right)$

Subscripts 
$0 \quad$ inlet channel

$m$ membrane surface

w pure water

\section{References}

[1] R. Ghidossi , D. Veyret, P. Moulin, Computational fluid dynamics applied to membranes: State of the art and opportunities, Chem. Eng. Process, 45 (2006) 437454.

[2] G.A. Fimbres-Weihs, D.E. Wiley, Review of 3D CFD modeling of flow and mass transfer in narrow spacer-filled channels in membrane modules, Chem. Eng. Process, 49 (2010) 759-781.

[3] V. Geraldes,V. Semião,M.N. Pinho, Numerical modelling of mass transfer in slits with semi-permeable membrane walls, Eng. Comput., 17 (2000) 192-217.

[4] V. Geraldes, V. Semião, M.M. Pinho, Flow and mass transfer modelling of nanofiltration, J. Membr. Sci., 191 (2001) 109-128.

[5] M. N. Pinho, V. Semião, V. Geraldes, Integrated modeling of transport processes in fluid/nanofiltration membrane systems, J. Membr. Sci., 206 (2002) 189-200.

[6] A .L. Ahmad, K.K. Lau, M.Z. Abu Bakar, S.R. Abd. Shukor, Integrated CFD simulation of concentration polarization in narrow membrane channel, Comput. Chem. Eng., 29 (2005) 2087-2095.

[7] S. Kim, E. M.V. Hoek, Modeling concentration polarization in reverse osmosis Processes, Desalination, 186 (2005) 111-128.

[8] L. Song, C. Liu, A total salt balance model for concentration polarization in crossflow reverse osmosis channels with shear flow, J. Membr. Sci., 401- 402 (2012) 313- 322.

[9] D. E .Wiley, D .F. Fletcher, Techniques for computational fluid dynamics modeling of flow in membrane channels, J. Membr. Sci., 211 (2003) 127-137.

[10] D.F. Fletcher, D.E. Wiley, A computational fluids dynamics study of buoyancy effects in reverse osmosis, J. Membr. Sci., 245 (2004) 175-181.

[11] A. Alexiadis, D.E. Wiley, A. Vishnoi, R.H.K. Lee, D.F. Fletcher, J. Bao, CFD modeling of reverse osmosis membrane flow and validation with experimental results, Desalination, 217 (2007) 242-250.

[12] M. Kostoglou, A. J. Karabelas, Comprehensive simulation of flat-sheet membrane element performance in steady state desalination, Desalination, 316 (2013) 91-102.

[13] J. Schwinge, D. E. Wiley, D. F. Fletcher, Simulation of the Flow around Spacer Filaments between Narrow Channel Walls. 1. Hydrodynamics, Ind. Eng. Chem. Res., 41 (2002) 2977-2987.

[14] J. Schwinge, D. E. Wiley, D. F. Fletcher, Simulation of the Flow around Spacer Filaments between Channel Walls. 2. Mass-Transfer Enhancement, Ind. Eng. Chem. Res., 41 (2002) 4879-4888.

[15] J. Schwinge, D.E. Wiley, D.F. Fletcher, A CFD study of unsteady flow in narrow spacer-filled channels for spiral wound membrane modules, Desalination, 146 (2002) 195-201. 
[16] J. Schwinge, D.E. Wiley, D.F. Fletcher, Simulation of unsteady flow and vortex shedding for narrow spacer-filled channels, Ind. Eng. Chem. Res., 42 (2003) 49624977.

[17] Z. Cao, D.E. Wiley, A.G. Fane, CFD simulations of net-type turbulence promoters in a narrow channel, J. Membr. Sci., 185 (2001) 157-176.

[18] C.P. Koutsou, S.G. Yiantsios, A.J. Karabelas, Numerical simulation of the flow in a plane-channel containing a periodic array of cylindrical turbulence promoters, J. Membr. Sci., 231 (2004) 81-90.

[19] A. Subramani, S. Kim, E. M.V. Hoek, Pressure, flow, and concentration profiles in open and spacer-filled membrane channels, J. Membr. Sci., 277 (2006) 7-17.

[20] S. Wardeh, H.P. Morvan, CFD simulations of flow and concentration polarization in spacer-filled channels for application to water desalination, Chem. Eng. Res. Des., 86 (2008) 1107-1116.

[21] S. Wardeh, H.P. Morvan, Detailed numerical simulations of flow mechanics and membrane performance in spacer-filled channels, flat and curved, Desalin. Water Treat., 1 (2009) 277-288.

[22] G. Shock, A. Miquel, Mass transfer and pressure loss in spiral wound modules, Desalination, 64 (1987) 339-352.

[23] C.P. Koutsou, S.G. Yiantsios, A.J. Karabelas, Direct numerical simulation of flow in spacer-filled channels: Effect of spacer geometrical characteristics, J. Membr. Sci., 291 (2007) 53-69.

[24] C.P. Koutsou, S.G. Yiantsios, and A.J. Karabelas, A numerical and experimental study of mass transfer in spacer-filled channels: Effects of spacer geometrical characteristics and Schmidt number, J. Membr. Sci., 326 (2009) 234-251.

[25] S. Ma, L. Song, S.L. Ong, W. J. Ng, A 2-D streamline upwind Petrov/Galerkin finite element model for concentration polarization in spiral wound reverse osmosis modules, J. Membr. Sci., 244 (2004) 129-139.

[26] S. Ma, L. Song, Numerical study on permeate flux enhancement by spacers in a crossflow reverse osmosis channel, J. Membr. Sci., 284 (2006) 102-109.

[27] V.Geraldes, V.Semião, M.N. Pinho, Flow management in nanofiltration spiral wound modules with ladder-type spacers, J. Membr. Sci., 203 (2002) 87-102.

[28] V. Geraldes , V. Semião , M .N. Pinho, The effect of the ladder-type spacers configuration in NF spiral-wound modules on the concentration boundary layers disruption, Desalination, 146 (2002) 187-194.

[29] V. Geraldes, V. Semião, M. N. Pinho, Hydrodynamics and Concentration polarisation and flow structure within nanofiltration spiral-wound modules with ladder-type spacers, Desalination, 157 (2003) 395-402.

[30] D. Dendukuri, S. K. Karode, and A. Kumar, Flow visualization through spacer filled channels by computational fluid dynamics-II: improved feed spacer designs, J. Membr. Sci., 249 (2005) 41-49.

[31] A .L. Ahmad, K.K. Lau, Impact of different spacer filaments geometries on 2D unsteady hydrodynamics and concentration polarization in spiral wound membrane channel, J. Membr. Sci., 262 (2005) 138-152.

[32] A.L. Ahmad, K.K. Lau, M.Z. Abu Bakar, Impact of different spacer filament geometries on concentration polarization control in narrow membrane channel, $\mathrm{J}$. Membr. Sci., 286 (2006) 77-92. 
[33] V. V. Ranade, A. Kumar, Fluid dynamics of spacer filled rectangular and curvilinear channels, J. Membr. Sci., 271 (2006) 1-15.

[34] G. Guillen, E. M.V. Hoek, Modeling the impacts of feed spacer geometry on reverse osmosis and nanofiltration processes, Chem. Eng. J., 149 (2009) 221-231.

[35] S. Oh, S.Wang, M.Park, J.H.Kim, Novel Spacer Design Using Topology Optimization in a Reverse Osmosis Channel, J. Fluids Eng., 136 (2014) 021201-12.

[36] M. Amokrane, D. Sadaoui , C.P. Koutsou, A.J. Karabelas , M. Dudeck , A study of flow field and concentration polarization evolution in membrane channels with twodimensional spacers during water desalination, J. Membr. Sci. (2014), http://dx.doi.org/10.1016/j.memsci.2014.11.029i.

[37] G.A. Fimbres-Weihs, D.E. Wiley, D.F. Fletcher, Unsteady flows with mass transfer in narrow zigzag spacer-filled channels: A numerical study, Ind. Eng. Chem. Res. 45 (2006) 6594-6603. 